\title{
ANALISIS EFETIVITAS RUANG HENTI KHUSUS (RHK) SEPEDA MOTOR PADA SIMPANG BERSINYAL DI PERSIMPANGAN RS. ABDUL MOELOEK BANDAR LAMPUNG, LAMPUNG
}

\author{
Aditya Mahatidanar ${ }^{1}$ \\ Idilham Afriansyah ${ }^{2}$ \\ ${ }^{1}$ Program Studi Teknik Sipil, Fakultas Teknik, Universitas Bandar Lampung, Indonesia \\ Email: Adityamahatidanar@dosen.ubl.ac.id ; aidilham18@gmail.com
}

\begin{abstract}
ABSTRAK
Accumulation of vehicles and irregular queues of two-wheeled vehicles at the time of red light are very influential on the performance of the intersection. To overcome the high proportion of motorbikes and the conflict problems that arise at the intersection, many alternative countermeasures have been made. One alternative that can be used is the Special Stop Room (RHK) lane. Which is expected to reduce queues and delays that are slowed down by vehicles, as well as by accidents that are passed. The purpose of this study was to analyze RHK activity, the percentage of RHK occupancy rate to capacity $(D c) R H K$ 1 in the morning period was 23\%, during the afternoon period was 19\%, in the afternoon period was $17 \%$ RHK 2 in the morning period was 38\%, in the afternoon period it is 33\%, in the afternoon period it is $27 \%$ RHK 3 in the morning period it is $46 \%$, in the afternoon period it is $39 \%$, in the afternoon period it is $32 \%$ based on the data obtained and from the results of the analysis carried out it can be ruled out that the level of effectiveness of RHK application on the line of Rs. Abdul Moeloek can be said to be less successful in determining the occupancy percentage, on average, less than $60 \%$.
\end{abstract}

Keyword : Effectiveness of Special Stopping Rooms (RHK), Motorbikes, Signaled Intersections 


\section{PENDAHULUAN}

Kepemilikan sepeda motor mengalami peningkatan yang sangat signifikan dari tahun ke tahun, Total penjualan sepeda motor di lampung pada tahun 2019 mencapai 6.487.430 unit atau mengalami kenaikan sebesar 1,63\% dari tahun 2018 yang hanya 6.383.111 unit. (Asosiasi Industri Sepeda Motor Indonesia/AISI,2019). Peningkatan kendaraan terutama sepeda motor akan berpengaruh pada analisis simpang bersinyal, disebabkan pengguna sepeda motor berusaha menggunakan secara optimal semua ruang yang ada di simpang. Untuk menanggulangi proporsi sepeda motor yang tinggi dan permasalahan konflik yang ditimbulkan di simpang sudah banyak dilakukan alternatif-alternatif penanggulangan. Salah satu alternatif yang dapat digunakan adalah lajur Ruang Henti Khusus (RHK). Penumpukan kendaraan bermotor yang tidak teratur terjadi di setiap pendekat simpang bersinyal. Penumpukan itu juga menutup pergerakan lalu lintas belok kiri langsung serta menghalangi pergerakan pejalan kaki.

\section{Pengertian Umum}

Persimpangan jalan dapat diartikan sebagai dua jalur atau lebih ruas jalan yang berpotongan, dan termasuk didalamnya fasilitas jalur jalan dan tepi jalan. Sedangkan setiap jalan yang memencar dan merupakan bagian dari persimpangan tersebut dikatakan dengan lengan persimpangan.

\section{Persimpangan}

Persimpangan adalah suatu lokasi dimana dua atau lebih ruas jalan bertemu atau berpotongan dan termasuk didalamnya fasilitas yang di perlukan untuk membantu kelancaran pergerakan lalu linatas di lokasi tersebut

\section{Simpang bersinyal}

Simpang bersinyal adalah suatu persimpangan yang terdiri dari beberapa lengan dan dilengkapi dengan pengaturan sinyal lampu lalu lintas (traffic light). Berdasarkan MKJI 1997, adapun tujuan penggunaan sinyal lampu lalu lintas (traffic light) pada persimpangan antara lain:

a. Menghindari kemacetan simpang akibat adanya konflik arus lalu lintas kendaraan dari masing-masing lengan.

b. Memberi kesempatan kepada kendaraan/dan pejalan kaki yang berasal dari jalan kecil yang memotong ke jalan utama.

c. Untuk mengurangi jumlah kecelakaan lalu lintas akibat tabrakan antara kendaraankendaraan dari arah bertentangan.

\section{Ruang Henti Khusus (RHK) Sepeda motor}

Ruang Henti Khusus (RHK) sepeda motor adalah sebuah marka jalan yang dibuat di dekat lampu pengatur lalu lintas (traffic light). Yang diberi warna merah dan diberi tanda atau gambar sepeda motor. Marka tersebut merupakan salah satu fasilitas bagi sepeda motor untuk berhenti di persimpangan selama lampu 
berwarna merah. Ruang henti khusus (Exclusive Stopping Space) untuk sepeda motor (RHK) adalah salah satu cara menanggulangi permasalahan penumpukan sepeda motor pada persimpangan bersinyal

\section{Syarat kebutuhan RHK}

\section{Persyaratan geometrik persimpangan}

Persyaratan geometri persimpangan bersinyal yang memperkenankan penempatan RHK, adalah:

1. Persimpangan yang memiliki minimum Dua lajur pada pendekat simpang dan pada kedua lajur pendekat tersebut bukan merupakan lajur belok langsung.

2. Lebar lajur pendekat simpang diisyaratkan 3,5 meter pada pendekat simpang sepeda motor Hal ini dimaksudkan agar terdapat ruang bagi sepeda motor untuk memasuki RHK.

\section{Persyaratan Kondisi Lain Lintas}

Persyaratan kondisi lalu untas untuk penempatan RHK pada bersinyal, adalah:

1. Bila penumpukan sepeda motor tanpa beraturan dengan jumlah minimal 30 sepeda motor perwaktu merah di pendekat simpang dua lajur atau minimal 45 sepeda motor perwaktu merah di pendekat simpang tiga lajur.

2. Untuk pendekat simpang Iebih dan tiga lajur, jumlah penumpukan sepeda motor secara tak beraturan tersebut minimum 15 sepeda motor per lajurnya. Jadi jumlah penumpukan sepeda motor minimum 15 sepeda motor dikali dengan jumlah lajur pada pendekat persimpangan.

\section{Perancangan RHK Sepeda motor rencana}

Dimensi RHK ditentukan dari dimensi ruang statis sepeda motor, sedangkan ruang statis sepeda motor diperoleh dari dimensi (panjang $\mathrm{x}$ lebar) rata-rata dari sepeda motor rencana.

\section{Perancangan tipe RHK}

\section{RHK tipe kotak (RHK tanpa lajur pendekat)}

RHK tipe kotak didesain apabila proporsi sepeda motor di tiap lajurnya relative sama.

Tabel 1 Kapasitas RHK tipe kotak dengan 2 lajur

\begin{tabular}{|c|c|c|c|c|}
\hline \multirow{2}{*}{$\begin{array}{c}\text { Panjang Lajur } \\
\text { RHK (L RHK) } \\
\text { (m) }\end{array}$} & \multicolumn{3}{|c|}{ Luas (m2) } & \multirow{2}{*}{$\begin{array}{l}\text { Kapasitas Seped } \\
\text { Motor Maksima }\end{array}$} \\
\hline & Lajur 1 & Lajur 2 & total & \\
\hline 8 & 28 & 28 & 56 & 37 \\
\hline 10 & 35 & 35 & 70 & 46 \\
\hline 12 & 42 & 42 & 84 & 56 \\
\hline
\end{tabular}

Sumber: Departemen Pekerjaan umum, 2015 
Tabel 2 Kapasitas RHK tipe kotak dengan 3

lajur

\begin{tabular}{|c|c|c|c|c|c|}
\hline \multirow{2}{*}{$\begin{array}{c}\text { Panjang Lajur } \\
\text { RHK (L RHK) } \\
\text { (m) }\end{array}$} & \multicolumn{4}{|c|}{ Luas (m2) } & \multirow{2}{*}{$\begin{array}{l}\text { Kapasitas Sepeda } \\
\text { Motor Maksimal }\end{array}$} \\
\hline & Lajur 1 & Lajur 2 & Lajur 3 & total & \\
\hline 8 & 28 & 28 & 28 & 84 & 56 \\
\hline 10 & 35 & 35 & 35 & 105 & 70 \\
\hline 12 & 42 & 42 & 42 & 126 & 84 \\
\hline
\end{tabular}

Sumber: Departemen Pekerjaan umum, 2015

RHK tipe P (RHK dengan lajur pendekat)

Perpanjangan RHK (RHK tipe P) dapat digunakan apabila volume sepeda motor yang bergerak pada lajur kiri melebihi $60 \%$ untuk RHK dengan dua lajur dari seluruh pergerakan sepeda motor pada pendekat simpang

Tabel 3 Kapasitas RHK tipe P dengan 2 lajur

\begin{tabular}{|c|c|c|c|c|c|}
\hline Panjang Sisi Kiri & Panjang Sisi & \multicolumn{3}{|c|}{ Luas $\left(\mathrm{m}^{2}\right)$} & Kapasistas \\
RHK (LRHK1) & Kanan (LRHK2) & Lajur 1 & Lajur 2 & Total & Sepeda \\
\hline 12 & 8 & 42 & 28 & 70 & 46 \\
\hline 14 & 10 & 49 & 35 & 84 & 56 \\
\hline 16 & 12 & 56 & 42 & 98 & 65 \\
\hline
\end{tabular}

Sumber: Departemen Pekerjaan umum, 2015

Tabel 4 Kapasitas RHK tipe P dengan 3 lajur

\begin{tabular}{|c|c|c|c|c|c|c|}
\hline \multirow{2}{*}{$\begin{array}{c}\text { Panjang Sisi Kir) } \\
\text { RHK(LRHKl) } \\
\text { (m) }\end{array}$} & \multirow{2}{*}{$\begin{array}{c}\text { Panjang Sisi } \\
\text { Kanan(LRHK2) } \\
(\mathrm{m}) \\
\end{array}$} & \multicolumn{4}{|c|}{ Luas $\left(m^{2}\right)$} & \multirow{2}{*}{$\begin{array}{r}\text { Kapasistas } \\
\text { Sepeda } \\
\text { Motor }\end{array}$} \\
\hline & & Lajur 1 & Lajur 2 & Lajur 3 & Total & \\
\hline 12 & 8 & 72 & 20 & Jo & 98 & 65 \\
\hline 14 & 10 & 49 & 35 & 35 & 119 & 79 \\
\hline 16 & 12 & 56 & 42 & 42 & 140 & 93 \\
\hline
\end{tabular}

Sumber: Departemen Pekerjaan umum, 2015

\section{METODOLOGI PENELITIAN}

Metodologi penelitian adalah suatu cara bagi peneliti untuk mendapatkan data yang dibutuhkan yang selanjutnya dapat digunakan untuk dianalisa sehingga memperoleh kesimpulan yang ingin dicapai dalam penelitian. Metodologi yang dipakai pada penelitian ini adalah dengan cara melakukan pengolahan data primer hasil survey lapangan serta mengumpulkan beberapa informasi yang dibutuhkan sebagai data sekunder

\section{Lokasi penelitian}

Penelitian ini di lakukan pada persimpangan Rs.Abdul Moeloek Jl Teuku Umar dan Jl. Dr Rivai seprti pada gambar 1.

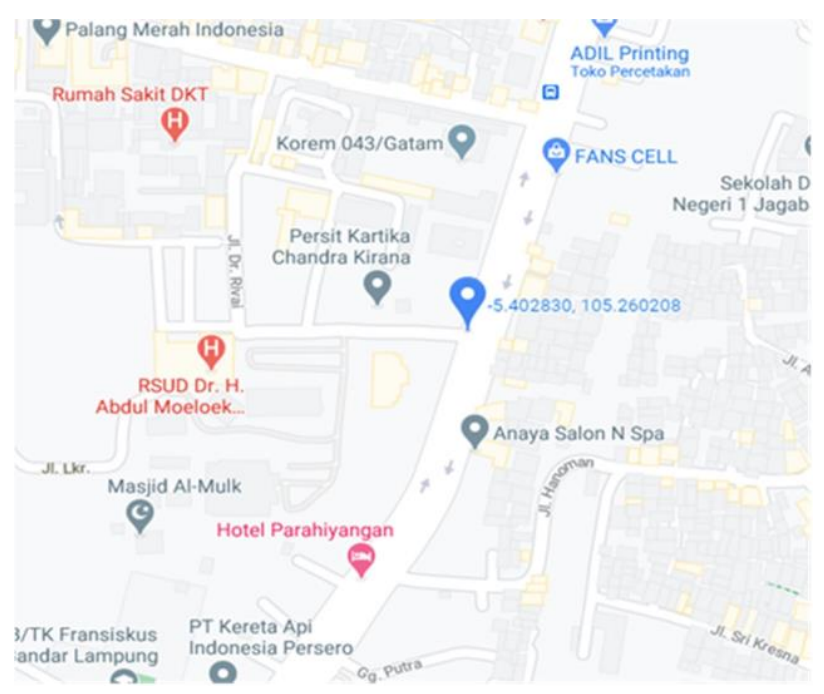

Gambar 1 lokasi penelitian 

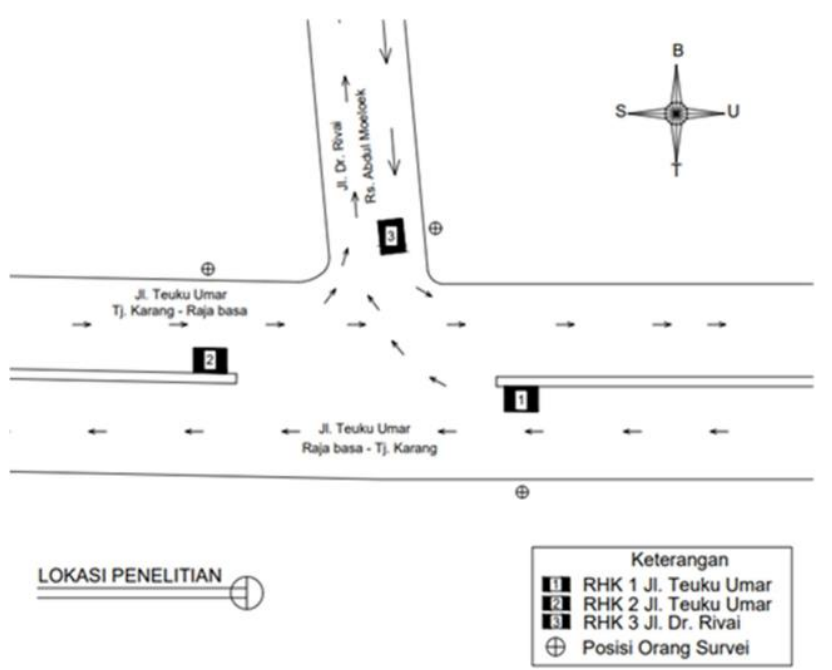

Gambar 2 Kondisi Geometrik simpangan

\section{Waktu penelitian}

Pengambilan data di lapangan dilakukan selama

2 hari yaitu pada hari Sabtu dan Senin dan terbagi menjadi 3 fase yaitu pagi, siang dan sore. Dengan mempertimbangkan tingkat keterisian dan pelanggaran . pengumpulan data lalu lintas dilakukan pada jam sibuk pagi yaitu pada pukul 06.30 - 08.30 dan siang 11.30 - 13.30 dan sore pada pukul 17.00 - 19.00 WIB.

\section{Analisa Data}

Data yang sudah diperoleh di Lapangan

dianalisis sebagai berikut :

1. Mengonversikan data jumlah keterisian dan pelanggaran RHK sehingga di dapat jumlah kesluruhan dan jumlah rata-rata.

2. Menghitung kapasitas RHK (C) dengan cara luas RHK di bagi dengan Luas sepeda motor

3. Menghitung jumlah keterisian RHK

a. Tingkat keterisian ruang henti khusus / Degree Capacity (Dc) Dengan cara: jumlah rata-rata sepeda motor yang masuk RHK selama 2 jam di bagi kapasitas

b. Keterisian RHK hanya oleh Sepeda Motor/Degree Capacity of Motorcycle (Dcm) Dengan cara: jumlah fase yang hanya terdapat depeda motor di bagi dengan jumlah keseluruhan fase

4. menghitung jumalah pelanggaran RHK sehingga di dapat jumlah rata-rata pelanggaran sepeda motor pada masingmasing RHK

5. membandikan hasil dari olah data, berapa persentase keberhasilan penerapan RHK pada simpang yang di analisis

\section{HASIL DAN PEMBAHASAN}

Sesuai dengan maksud dan tujuan penelitian ini di lakukan yaitu untuk menganalisa Efektivitas RHK Sepeda Motor . Berikut pembahasannya di tinjau dari Tingkat Keterisian RHK Sepeda Motor dan Tingkat Pelanggaran pengguna RHK Sepeda Motor.

\section{Analisa tingkat Keterisian Ruang Henti Khusus (RHK)}

\section{Kapasitas}

Analisa perhitungan tingkat keterisian ruang henti khusus (RHK) sepeda motor dilakukan dengan cara tahap pertama membagi luas RHK dengan luas kapasitas sepeda motorLuas area ruang henti khusus didapat dari pengukuran secara langsung dilapangan, sedangkan luas 
sepeda motor didapat dengan melihat pada "Pedoman Perencanaan Ruang Henti Khusus (RHK) Sepeda Motor pada Simpang Bersinyal di Kawasan Perkotaan.

\section{Prosentase keterisian RHK dibagi menjadi} dua yaitu:

1. Hasil analisis presentase keterisian Dc dan Dcm RHK pada tiga lokasi penelitian ditunjukkan pada Tabel 5 Tabel 6 Tabel 7 Tabel 8, berikut:

Tabel 5 Tingkat keterisian RHK (Dc)

\begin{tabular}{|c|c|c|c|c|c|}
\hline \multicolumn{6}{|c|}{ WEEKEND (SABTU, 23 JANUARI 2021) } \\
\hline No & Waktu & Fase & $\begin{array}{c}\text { Jumlah rata-rata } \\
\text { Sepeda Motor } \\
\text { yang ada di kotak } \\
\text { RHK selama } 2 \\
\text { Jam }\end{array}$ & $\begin{array}{c}\text { kapasitas } \\
\text { (RHK) }\end{array}$ & $\begin{array}{c}\text { Tingkat } \\
\text { Keterisian }\end{array}$ \\
\hline \multicolumn{6}{|c|}{ RHK 1 Jalan Teuku Umar dari Raja Basa - Tanjung Karang } \\
\hline 1 & PAGI Jam 06.30-08.30 & 77 & 1.6 & 8 & $20 \%$ \\
\hline 2 & SIANG Jam 11.30-13.30 & 77 & 1.4 & 8 & $18 \%$ \\
\hline 3 & SORE Jam 17.00-19.00 & 77 & 1.5 & 8 & $19 \%$ \\
\hline \multicolumn{6}{|c|}{ RHK 2 Jalan Teuku Umar dari Tanjung Karang - Raja Basa } \\
\hline No & Waktu & Fase & $\begin{array}{c}\text { Jumlah rata-rata } \\
\text { Sepeda Motor } \\
\text { yang ada di kotak } \\
\text { RHK selama } 2 \\
\text { Jam }\end{array}$ & $\begin{array}{c}\text { kapasitas } \\
\text { (RHK) }\end{array}$ & $\begin{array}{c}\text { Tingkat } \\
\text { Keterisian }\end{array}$ \\
\hline 1 & PAGI Jam 06.30-08.30 & 73 & 8.3 & 23 & $36 \%$ \\
\hline 2 & SIANG Jam 11.30-13.30 & 73 & 6.9 & 23 & $30 \%$ \\
\hline 3 & SORE Jam 17.00-19.00 & 73 & 7.2 & 23 & $31 \%$ \\
\hline \multicolumn{6}{|c|}{ RHK 3 Jalan Dr.Rivai dari Rs. Abdul Moloek - Tanjung Karang } \\
\hline No & Waktu & Fase & $\begin{array}{c}\text { Jumlah rata-rata } \\
\text { Sepeda Motor } \\
\text { yang ada di kotak } \\
\text { RHK selama } 2 \\
\text { Jam }\end{array}$ & $\begin{array}{c}\text { kapasitas } \\
\text { (RHK) }\end{array}$ & $\begin{array}{c}\text { Tingkat } \\
\text { Keterisian }\end{array}$ \\
\hline 1 & PAGI Jam 06.30-08.30 & 76 & 5.2 & 13 & $40 \%$ \\
\hline 2 & SIANG Jam 11.30-13.30 & 76 & 4.9 & 13 & $38 \%$ \\
\hline 3 & SORE Jam 17.00-19.00 & 76 & 4.9 & 13 & $38 \%$ \\
\hline
\end{tabular}

Sumber: Tugas Akhir Analisis Efektivitas Ruang

\section{Henti Khusus pada Simpang Bersinyal di Kota}

Bandar lampung, 2021

Tabel di atas memberikan informasi:

RHK 1 pada periode pagi adalah 20\%, Persentase keterisian RHK pada periode siang adalah 18\%, Persentase keterisian RHK pada periode sore adalah $19 \%$. RHK 2 pada periode pagi adalah 36\%, Persentase keterisian RHK pada periode siang adalah 30\%, Persentase keterisian RHK pada periode sore adalah $31 \%$.

RHK 3 pada periode pagi adalah 40\%, Persentase keterisian RHK pada periode siang adalah 38\%, Persentase keterisian RHK pada periode sore adalah $38 \%$.

Tabel 6 Tingkat keterisian RHK (Dc)

\begin{tabular}{|c|c|c|c|c|c|}
\hline \multicolumn{6}{|c|}{ WEEKDAY (SENIN, 25 JANUARI 2021) } \\
\hline \multicolumn{6}{|c|}{ RHK 1 Jalan Teuku Umar dari Raja basa - Tanjung Karang } \\
\hline No & Waktu & Fase & $\begin{array}{c}\text { Jumlah rata-rata } \\
\text { Sepeda Motor yang } \\
\text { ada di kotak RHK } \\
\text { selama } 2 \text { Jam }\end{array}$ & $\begin{array}{c}\text { kapasitas } \\
\text { (RHK) }\end{array}$ & $\begin{array}{r}\text { Tingkat } \\
\text { Keterisian }\end{array}$ \\
\hline 1 & PAGI Jam 06.30-08.30 & 72 & 2.0 & 8 & $25 \%$ \\
\hline 2 & SIANG Jam 12.00-14.00 & 72 & 1.6 & 8 & $20 \%$ \\
\hline 3 & SORE Jam 17.00-19.00 & 72 & 1.1 & 8 & $14 \%$ \\
\hline \multicolumn{6}{|c|}{ WEEKDAY (SENIN, 25 JANUARI 2021) } \\
\hline \multicolumn{6}{|c|}{ RHK 2 Jalan Teuku Umar dari Tanjung Karang - Raja Basa } \\
\hline No & Waktu & Fase & $\begin{array}{c}\text { Jumlah rata-rata } \\
\text { Sepeda Motor yang } \\
\text { ada di kotak RHK } \\
\text { selama } 2 \text { Jam }\end{array}$ & $\begin{array}{c}\text { kapasitas } \\
\text { (RHK) }\end{array}$ & $\begin{array}{r}\text { Tingkat } \\
\text { Keterisian }\end{array}$ \\
\hline 1 & PAGI Jam 06.30-08.30 & 71 & 9.2 & 23 & $40 \%$ \\
\hline 2 & SIANG Jam 12.00-14.00 & 71 & 8.3 & 23 & $36 \%$ \\
\hline 3 & SORE Jam 17.00-19.00 & 71 & 5.1 & 23 & $22 \%$ \\
\hline \multicolumn{6}{|c|}{ WEEKDAY (SENIN, 25 JANUARI 2021) } \\
\hline \multicolumn{6}{|c|}{ RHK 3 Jalan Dr.Rivai dari Rs. Abdul Moloek - Tanjung Karang } \\
\hline No & Waktu & Fase & $\begin{array}{c}\text { Jumlah rata-rata } \\
\text { Sepeda Motor yang } \\
\text { ada di kotak RHK } \\
\text { selama } 2 \text { Jam }\end{array}$ & $\begin{array}{c}\text { kapasitas } \\
\text { (RHK) }\end{array}$ & $\begin{array}{r}\text { Tingkat } \\
\text { Keterisian }\end{array}$ \\
\hline 1 & PAGI Jam 06.30-08.30 & 71 & 6.8 & 13 & $52 \%$ \\
\hline 2 & SIANG Jam 12.00-14.00 & 71 & 5.2 & 13 & $40 \%$ \\
\hline 3 & SORE Jam 17.00-19.00 & 71 & 3.5 & 13 & $27 \%$ \\
\hline
\end{tabular}

Sumber: Tugas Akhir Analisis Efektivitas Ruang

\section{Henti Khusus pada Simpang Bersinyal di Kota}

Bandar lampung, 2021

Tabel di atas memberikan informasi: 
RHK 1 pada periode pagi adalah 25\%, Persentase keterisian RHK pada periode siang adalah 20\%, Persentase keterisian RHK pada periode sore adalah $14 \%$.

RHK 2 pada periode pagi adalah 40\%, Persentase keterisian RHK pada periode siang adalah $36 \%$, Persentase keterisian RHK pada periode sore adalah $22 \%$.

RHK 3 pada periode pagi adalah 52\%, Persentase keterisian RHK pada periode siang adalah $40 \%$, Persentase keterisian RHK pada periode sore adalah $27 \%$.

Tabel 7 Tingkat keterisian RHK hanya oleh sepeda motor (Dcm)

\begin{tabular}{|c|c|c|c|c|}
\hline \multicolumn{5}{|c|}{ WEEKEND (SABTU, 23 JANUARI 2021) } \\
\hline \multicolumn{5}{|c|}{ RHK 1 Jalan Teuku Umar dari Raja basa - Tanjung Karang } \\
\hline No & Waktu & $\begin{array}{c}\text { Jumlah fase } \\
\text { Sepeda Motor } \\
\text { tanpa kendaraan } \\
\text { lain selama } 2 \text { Jam }\end{array}$ & Fase & $\begin{array}{c}\text { Tingkat } \\
\text { Keterisian } \\
(\%)\end{array}$ \\
\hline 1 & PAGI Jam 06.30-08.30 & 69 & 77 & 0.8961039 \\
\hline 2 & SIANG Jam 11.30-13.30 & 71 & 77 & 0.9220779 \\
\hline 3 & SORE Jam 17.00-19.00 & 69 & 77 & 0.8961039 \\
\hline \multicolumn{5}{|c|}{ WEEKEND (SABTU, 23 JANUARI 2021) } \\
\hline \multicolumn{5}{|c|}{ RHK 2 Jalan Teuku Umar dari Tanjung Karang - Raja Basa } \\
\hline No & Waktu & $\begin{array}{c}\text { Jumlah fase } \\
\text { Sepeda Motor } \\
\text { tanpa kendaraan } \\
\text { lain selama } 2 \text { Jam }\end{array}$ & Fase & $\begin{array}{c}\text { Tingkat } \\
\text { Keterisian } \\
(\%)\end{array}$ \\
\hline 1 & PAGI Jam 06.30-08.30 & 61 & 73 & 0.8356164 \\
\hline 2 & SIANG Jam 11.30-13.30 & 60 & 73 & 0.8219178 \\
\hline 3 & SORE Jam 17.00-19.00 & 57 & 73 & 0.7808219 \\
\hline \multicolumn{5}{|c|}{ WEEKEND (SABTU, 23 JANUARI 2021) } \\
\hline \multicolumn{5}{|c|}{ RHK 3 Jalan Dr.Rivai dari Rs. Abdul Moloek - Tanjung Karang } \\
\hline No & Waktu & $\begin{array}{c}\text { Jumlah fase } \\
\text { Sepeda Motor } \\
\text { tanpa kendaraan } \\
\text { lain selama } 2 \text { Jam }\end{array}$ & Fase & $\begin{array}{c}\text { Tingkat } \\
\text { Keterisian } \\
(\%)\end{array}$ \\
\hline 1 & PAGI Jam 06.30-08.30 & 46 & 76 & 0.6052632 \\
\hline 2 & SIANG Jam 11.30-13.30 & 42 & 76 & 0.5526316 \\
\hline 3 & SORE Jam 17.00-19.00 & 55 & 76 & 0.7236842 \\
\hline
\end{tabular}

Sumber: Tugas Akhir Analisis Efektivitas Ruang

Henti Khusus pada Simpang Bersinyal di Kota

\section{Bandar lampung, 2021}

Tabel 7 di atas memberikan informasi:
Persentase Keterisian RHK 1 pada periode pagi adalah 90\%, Persentase keterisian RHK pada periode siang adalah $92 \%$, Persentase keterisian RHK pada periode sore adalah $90 \%$.

RHK 2 pada periode pagi adalah 84\%, Persentase keterisian RHK pada periode siang adalah $82 \%$, Persentase keterisian RHK pada periode sore adalah $78 \%$.

RHK 3 pada periode pagi adalah $61 \%$, Persentase keterisian RHK pada periode siang adalah 55\%, Persentase keterisian RHK pada periode sore adalah $72 \%$.

Tabel 8 Tingkat keterisian RHK hanya oleh sepeda motor (Dcm)

\begin{tabular}{|c|c|c|c|c|}
\hline \multicolumn{5}{|c|}{ WEEKEND (SABTU, 23 JANUARI 2021) } \\
\hline \multicolumn{5}{|c|}{ RHK 1 Jalan Teuku Umar dari Raja basa - Tanjung Karang } \\
\hline No & Waktu & $\begin{array}{c}\text { Jumlah fase Sepeda } \\
\text { Motor tanpa } \\
\text { kendaraan lain } \\
\text { selama 2 Jam }\end{array}$ & Fase & $\begin{array}{c}\text { Tingkat } \\
\text { Keterisian } \\
(\%)\end{array}$ \\
\hline 1 & $\begin{array}{l}\text { PAGI Jam 06.30-08.30 } \\
\end{array}$ & 69 & 77 & $90 \%$ \\
\hline 2 & SIANG Jam 11.30-13.30 & 71 & 77 & $92 \%$ \\
\hline 3 & SORE Jam 17.00-19.00 & 69 & 77 & $90 \%$ \\
\hline \multicolumn{5}{|c|}{ WEEKEND (SABTU, 23 JANUARI 2021) } \\
\hline \multicolumn{5}{|c|}{ RHK 2 Jalan Teuku Umar dari Tanjung Karang - Raja Basa } \\
\hline No & Waktu & $\begin{array}{c}\text { Jumlah fase Sepeda } \\
\text { Motor tanpa } \\
\text { kendaraan lain } \\
\text { selama 2 Jam }\end{array}$ & Fase & $\begin{array}{c}\text { Tingkat } \\
\text { Keterisian } \\
(\%)\end{array}$ \\
\hline 1 & PAGI Jam 06.30-08.30 & 61 & 73 & $84 \%$ \\
\hline 2 & SIANG Jam 11.30-13.30 & 60 & 73 & $82 \%$ \\
\hline 3 & SORE Jam 17.00-19.00 & 57 & 73 & $78 \%$ \\
\hline \multicolumn{5}{|c|}{ WEEKEND (SABTU, 23 JANUARI 2021) } \\
\hline \multicolumn{5}{|c|}{ RHK 3 Jalan Dr.Rivai dari Rs. Abdul Moloek - Tanjung Karang } \\
\hline No & Waktu & $\begin{array}{c}\text { Jumlah fase Sepeda } \\
\text { Motor tanpa } \\
\text { kendaraan lain } \\
\text { selama 2 Jam }\end{array}$ & Fase & $\begin{array}{c}\text { Tingkat } \\
\text { Keterisian } \\
(\%)\end{array}$ \\
\hline 1 & PAGI Jam 06.30-08.30 & 46 & 76 & $61 \%$ \\
\hline 2 & SIANG Jam 11.30-13.30 & 42 & 76 & $55 \%$ \\
\hline 3 & SORE Jam 17.00-19.00 & 55 & 76 & $72 \%$ \\
\hline
\end{tabular}


Sumber: Tugas Akhir Analisis Efektivitas Ruang

Henti Khusus pada Simpang Bersinyal di Kota

Bandar lampung, 2021

Tabel 8 di atas memberikan informasi:

RHK 1 pada periode pagi adalah $81 \%$, Persentase keterisian RHK pada periode siang adalah 92\%, Persentase keterisian RHK pada periode sore adalah $92 \%$.

RHK 2 pada periode pagi adalah 94\%, Persentase keterisian RHK pada periode siang adalah $83 \%$, Persentase keterisian RHK pada periode sore adalah $87 \%$.

RHK 3 pada periode pagi adalah 69\%, Persentase keterisian RHK pada periode siang adalah $86 \%$, Persentase keterisian RHK pada periode sore adalah $55 \%$.

\section{Analisa tingkat Pelanggaran Ruang Henti Khusus (RHK)}

perhitungan tingkat pelanggaran ruang henti khusus (RHK) sepeda motor dilakukan dengan cara membagi jumlah sepeda motor yang melanggar marka melintang garis henti RHK dengan Jumlah keseluruhan sepeda motor yang berhenti pada kotak RHK, Klasifikasi tingkat pelanggaran RHK ditunjukan pada Tabel 9 Tabel 10, berikut:

Tabel 9 Rata-rata tingkat pelanggaran RHK

\begin{tabular}{|c|c|c|c|c|c|}
\hline \multicolumn{6}{|c|}{ WEEKEND (SABTU, 23 JANUARI 2021) } \\
\hline \multicolumn{6}{|c|}{ RHK 1 Jalan Teuku Umar dari Raja basa - Tanjung Karang } \\
\hline \multirow[t]{2}{*}{ No } & \multirow[t]{2}{*}{ Waktu } & \multirow[t]{2}{*}{$\begin{array}{c}\text { Jumlah } \\
\text { Fase }\end{array}$} & $\begin{array}{c}\text { JumlahSepeda } \\
\text { Motor yang } \\
\text { melanggar } \\
\text { RHK selama } 2 \\
\text { jam(JP) }\end{array}$ & $\begin{array}{c}\text { Jumlah Sepeda } \\
\text { Motor yang } \\
\text { berhenti di } \\
\text { kotak RHK (JT) }\end{array}$ & \multirow[t]{2}{*}{$\begin{array}{c}\text { Rata-rata } \\
\text { Tingkat } \\
\text { Pelanggaran } \\
\text { (RTP) }\end{array}$} \\
\hline & & & (Unit) & (Unit) & \\
\hline 1 & PAGI Jam 06.00 sampai 08.00 & 77 & 55 & 118 & $47 \%$ \\
\hline 2 & \begin{tabular}{|l|} 
SIANG Jam 12.00 sampai 14.00 \\
\end{tabular} & 77 & $\overline{15}$ & 118 & $13 \%$ \\
\hline 3 & SORE Jam 16.00 sampai 18.00 & 77 & 7 & 118 & $6 \%$ \\
\hline \multicolumn{6}{|c|}{ WEEKEND (SABTU, 23 JANUARI 2021) } \\
\hline \multicolumn{6}{|c|}{ RHK 2 Jalan Teuku Umar dari Tanjung Karang - Raja Basa } \\
\hline \multirow[t]{2}{*}{ No } & \multirow[t]{2}{*}{ Waktu } & \multirow[t]{2}{*}{$\begin{array}{c}\text { Jumlah } \\
\text { Fase }\end{array}$} & \begin{tabular}{|c} 
Jumlah Sepeda \\
Motor yang \\
melanggar \\
RHK selama 2 \\
jam $(\mathrm{JP})$ \\
\end{tabular} & $\begin{array}{c}\text { Jumlah Sepeda } \\
\text { Motor yang } \\
\text { berhenti di } \\
\text { kotak RHK (JT) }\end{array}$ & \multirow[t]{2}{*}{$\begin{array}{c}\text { Rata-rata } \\
\text { Tingkat } \\
\text { Pelanggaran } \\
\text { (RTP) }\end{array}$} \\
\hline & & & (Unit) & (Unit) & \\
\hline 1 & PAGI Jam 06.00 sampai 08.00 & 73 & 425 & 1629 & $26 \%$ \\
\hline 2 & SIANG Jam 12.00 sampai 14.00 & 73 & 551 & 1629 & $34 \%$ \\
\hline 3 & \begin{tabular}{|l|} 
SORE Jam 16.00 sampai 18.00 \\
\end{tabular} & 73 & 471 & 1629 & $29 \%$ \\
\hline \multicolumn{6}{|c|}{ WEEKEND (SABTU, 23 JANUARI 2021) } \\
\hline \multicolumn{6}{|c|}{ RHK 3 Jalan Dr.Rivai dari Rs. Abdul Moloek - Tanjung Karang } \\
\hline \multirow[t]{2}{*}{ No } & \multirow[t]{2}{*}{ Waktu } & \multirow[t]{2}{*}{$\begin{array}{c}\text { Jumlah } \\
\text { Fase }\end{array}$} & $\begin{array}{c}\text { Jumlah Sepeda } \\
\text { Motor yang } \\
\text { melanggar } \\
\text { RHK selama } 2 \\
\text { jam (JP) }\end{array}$ & $\begin{array}{c}\text { Jumlah Sepeda } \\
\text { Motor yang } \\
\text { berhenti di } \\
\text { kotak RHK (JT) }\end{array}$ & \multirow[t]{2}{*}{$\begin{array}{c}\text { Rata-rata } \\
\text { Tingkat } \\
\text { Pelanggaran } \\
\text { (RTP) }\end{array}$} \\
\hline & & & (Unit) & (Unit) & \\
\hline 1 & \begin{tabular}{|l|} 
PAGI Jam 06.00 sampai 08.00 \\
\end{tabular} & 76 & 267 & 1119 & $24 \%$ \\
\hline 2 & SIANG Jam 12.00 sampai 14.00 & 76 & 113 & 1119 & $10 \%$ \\
\hline 3 & \begin{tabular}{|l|} 
SORE Jam 16.00 sampai 18.00 \\
\end{tabular} & 76 & 81 & 1119 & $7 \%$ \\
\hline
\end{tabular}

Sumber: Tugas Akhir Analisis Efektivitas Ruang Henti Khusus pada Simpang Bersinyal di Kota Bandar lampung, 2021

Tabel 9 di atas memberikan informasi:

RHK 1 pada periode pagi adalah $47 \%$, Persentase keterisian RHK pada periode siang adalah 13\%, Persentase keterisian RHK pada periode sore adalah $6 \%$.

RHK 2 pada periode pagi adalah 26\%, Persentase keterisian RHK pada periode siang 
adalah 34\%, Persentase keterisian RHK pada periode sore adalah $29 \%$.

RHK 3 pada periode pagi adalah 24\%, Persentase keterisian RHK pada periode siang adalah $10 \%$, Persentase keterisian RHK pada periode sore adalah $7 \%$.

Tabel 10 Rata-rata tingkat pelanggaran RHK (Dcm)

\begin{tabular}{|c|c|c|c|c|c|}
\hline \multicolumn{6}{|c|}{ WEEKDAY (SENIN, 25 JANUARI 2021) } \\
\hline \multicolumn{6}{|c|}{ RHK 1 Jalan Teuku Umar dari Raja basa - Tanjung Karang } \\
\hline \multirow[t]{2}{*}{ No } & \multirow[t]{2}{*}{ Waktu } & \multirow[t]{2}{*}{$\begin{array}{c}\text { Jumlah } \\
\text { Fase }\end{array}$} & \begin{tabular}{|c} 
Jumlah Sepeda \\
Motor yang \\
melanggar RHK \\
selama 2 jam \\
(JP)
\end{tabular} & $\begin{array}{c}\text { Jumlah } \\
\text { Sepeda } \\
\text { Motor yang } \\
\text { berhenti di } \\
\text { kotak RHK } \\
(\mathrm{JT}) \\
\end{array}$ & \multirow[t]{2}{*}{$\begin{array}{c}\text { Rata-rata } \\
\text { Tingkat } \\
\text { Pelanggaran } \\
\text { (RTP) }\end{array}$} \\
\hline & & & (Unit) & (Unit) & \\
\hline 1 & PAGI Jam 06.00 sampai 08.00 & 72 & 44 & 162 & $27 \%$ \\
\hline 2 & SIANG Jam 12.00 sampai 14.00 & 72 & 14 & 162 & $9 \%$ \\
\hline 3 & SORE Jam 16.00 sampai 18.00 & 72 & 7 & 162 & $4 \%$ \\
\hline \multicolumn{6}{|c|}{ WEEKDAY (SENIN, 25 JANUARI 2021) } \\
\hline \multicolumn{6}{|c|}{ RHK 2 Jalan Teuku Umar dari Tanjung Karang - Raja Basa } \\
\hline \multirow[t]{2}{*}{ No } & \multirow[t]{2}{*}{ Waktu } & \multirow[t]{2}{*}{$\begin{array}{c}\text { Jumlah } \\
\text { Fase }\end{array}$} & \begin{tabular}{|c|} 
Jumlah Sepeda \\
Motor yang \\
melanggar RHK \\
selama 2 jam \\
(JP) \\
\end{tabular} & \begin{tabular}{|c|} 
Jumlah \\
Sepeda \\
Motor yang \\
berhenti di \\
kotak RHK \\
$(\mathrm{JT})$ \\
\end{tabular} & \multirow[t]{2}{*}{$\begin{array}{c}\text { Rata-rata } \\
\text { Tingkat } \\
\text { Pelanggarar } \\
\text { (RTP) }\end{array}$} \\
\hline & & & (Unit) & (Unit) & \\
\hline 1 & PAGI Jam 06.00 sampai 08.00 & 71 & 643 & 1572 & $41 \%$ \\
\hline 2 & SIANG Jam 12.00 sampai 14.00 & 71 & 651 & 1572 & $41 \%$ \\
\hline 3 & SORE Jam 16.00 sampai 18.00 & 71 & 269 & 1572 & $17 \%$ \\
\hline \multicolumn{6}{|c|}{ WEEKDAY (SENIN, 25 JANUARI 2021) } \\
\hline \multicolumn{6}{|c|}{ RHK 3 Jalan Dr.Rivai dari Rs. Abdul Moloek - Tanjung Karang } \\
\hline \multirow[t]{2}{*}{ No } & \multirow[t]{2}{*}{ Waktu } & \multirow[t]{2}{*}{$\begin{array}{c}\text { Jumlah } \\
\text { Fase }\end{array}$} & \begin{tabular}{|c} 
Jumlah Sepeda \\
Motor yang \\
melanggar RHK \\
selama 2 jam \\
(JP)
\end{tabular} & $\begin{array}{c}\text { Jumlah } \\
\text { Sepeda } \\
\text { Motor yang } \\
\text { berhenti di } \\
\text { kotak RHK } \\
\text { (JT) }\end{array}$ & \multirow[t]{2}{*}{$\begin{array}{c}\text { Rata-rata } \\
\text { Tingkat } \\
\text { Pelanggarar } \\
\text { (RTP) }\end{array}$} \\
\hline & & & (Unit) & (Unit) & \\
\hline 1 & PAGI Jam 06.00 sampai 08.00 & 71 & 276 & 1004 & $27 \%$ \\
\hline 2 & SIANG Jam 12.00 sampai 14.00 & 71 & 166 & 1004 & $17 \%$ \\
\hline 3 & SORE Jam 16.00 sampai 18.00 & 71 & 95 & 1004 & $9 \%$ \\
\hline
\end{tabular}

Sumber: Tugas Akhir Analisis Efektivitas Ruang Henti Khusus pada Simpang Bersinyal di Kota Bandar lampung, 2021
Tabel 10 di atas memberikan informasi:

RHK 1 pada periode pagi adalah 27\%, Persentase keterisian RHK pada periode siang adalah 9\%, Persentase keterisian RHK pada periode sore adalah $4 \%$. RHK 2 pada periode pagi adalah $41 \%$, Persentase keterisian RHK pada periode siang adalah $41 \%$, Persentase keterisian RHK pada periode sore adalah $17 \%$. RHK 3 pada periode pagi adalah 27\%, Persentase keterisian RHK pada periode siang adalah $17 \%$, Persentase keterisian RHK pada periode sore adalah $9 \%$.

\section{Kesimpulan}

Berdasarkan hasil dari analisa Analisis Efektivitas Ruang henti Khusus (RHK) sepeda motor pada persimpangan Rs. Abdul Moeloek Jalan Teuku Umar dan Jalan Dr. Rivai dapat di simpulkan bahwa:

1. Penerapan Ruang Henti Khusus pada pada persimpangan Rs. Abdul Moeloek Jalan Teuku Umar dan Jalan Dr. Rivai dapat mengurangi panjangnya antrian pada saat nyala lampu merah

2. Peresentase tingkat keterisian RHK terhadap kapasitas (Dc)

- RHK 1 pada priode pagi adalah 23\%, pada priode siang adalah $19 \%$, pada priode sore adalah $17 \%$

- RHK 2 pada priode pagi adalah 38\%, pada priode siang adalah $33 \%$, pada priode sore adalah $27 \%$ 
- RHK 3 pada priode pagi adalah 46\%, pada priode siang adalah $39 \%$, pada priode sore adalah $32 \%$

3. Dari hasil olah data di atas dapat disimpulkan bahwa Evektifitas penerapan RHK pada persimpangan Rs. Abdul Moeloek dapat dikatakan kurang berhasil di terapkan karna peresentase keterisianya rata-rata kurang dari $60 \%$.

\section{Saran}

1. Diperlukan akses lajur khusus untuk menuju area RHK yang bertujuan untuk mempermudah para pengendara sepeda motor menjangkau kotak RHK terutama pada jam-jam sibuk.

2. Diperlukan rambu-rambu tambahan yang mengarah ke Ruang Henti Khusus agar pengendara lain selain sepeda motor tidak berhenti di area RHK

3. Perlunya sosialisai kepada pengguna jalan raya tentang fungsi dan manfaat Ruang Henti Khusus, agar para pengguna jalan raya faham guna di terapkanya RHK, sehingga dapat tercapai lingkungan jalan yang tertib dan lancar

\section{DAFTAR USTAKA}

Badan Pusat Statistik, BPS (2019), Kepadatan Penduduk B.Lampung Menurut Kabupaten/Kota Tahun 2010-2019, Badan Pusat Statistik
Departemen Pekerjaan Umum, 1997, Manual Kapasitas Jalan Indonesia, Departemen Pekerjaan Umum.

(Asosiasi Industri Sepeda Motor Indonesia/AISI,2019). Data Peningkatan sepeda motor Provinsi Lampung

Departemen Pekerjaan Umum

(No:52/SE/M/2015) Pedoman Perancangan

Ruang Henti Khusus (RHK) Sepeda Motor Pada

Simpang Bersinyal Di Kawasan Perkotaan

Saeprima, K. A. (2014). Analisis Efektivitas

Ruang Henti Khusus (RHK) sepeda motor,

Sarjana Teknik Sipil Universitas Bandar Lampung, Lampung

Mentri Perhubungan (Nomor: KM 61 Tahun

1963) tentang Rambu-Rambu Lalu Lintas Jalan LINTAS, Balai Teknik Lalu; JALAN, Lingkungan. Modul Pelatihan Perancangan RHK. Pusat Penelitian dan Pengembangan Jalan dan Jembatan. Bandung, 2012.

HARY, P. Diktat Rekayasa Lalu Lintas. Malang: Beta Offset, 2008.

Undang-Undang Nomor 22 Tahun (2009:105) tentang Lalu Lintas dan Angkutan Jalan, bagian keempat tentang tata cara berlalu lintas

Balai Teknik Lalu Lintas dan Lingkungan Jalan, 2012, Survei Lalu Lintas

(Pusjatan, 2012). Tingkat Pelanggaran RHK

Menurut Effendy (2008:14) et al. Efektivitas Ruang Henti Khusus Dalam Menciptakan Tertib Lalu Lintas. 